WorldCAT at \#187304223. There is no fee for access. Its ISSN is 1940-9702. http://www.cathla.org/round-tables/74-cataloging-a-classifications

Rob, who also serves as the subject liaison for German literature with responsibility for collection development at Notre Dame, included a lead article in the first issue dated October 2007 about the life of Father Oliver Leonard Kapsner (1902-1991). Written by Sister M. Dorothy Neuhofer, O.S.B., former CLA president, the premier article explains why the newsletter is named in his memory. Rob cordially solicits contributions. Send them to rkusmer@,nd.edu.

Submitted by

Thomas Duszak, Head Cataloging Section

State Library of Pennsylvania

\title{
ATLA FUNNEL PROJECTS MAKE MAJOR CONTRIBUTIONS TO RELIGIOUS RESOURCES
}

During the fourteen months from Oct. 1, 2009 to Nov. 30, 2010, the sixteen active members of the ATLA NACO Funnel Project created 1074 new name authority records in the areas of personal names, corporate and conference names, geographic names and uniform titles. In addition, there were 216 existing authority records which were modified in some way, primarily in the area of additional cross references or additional information in the notes. During this period, two members achieved independence. Denise Pakala is now independent in the creation of personal names and Michael Bradford is independent in the creation of corporate, conference, and geographic names.

The three active members of the CONSER Funnel Project, during this same fourteen month period, authenticated 250 serial records. This includes both original cataloging and the authentication of records contributed to the OCLC database by non-CONSER catalogers. During this same period, 96 CONSER records were updated to add or change information based on later issues.

Finally, during this same period, the SACO Funnel, coordinated by Eric Friede, proposed 5 new subject headings and 8 new or changed classification numbers.

Any ATLA member wishing to join either the NACO or CONSER funnel projects should email Judy Knop at jknop@atla.com. Training is available periodically at the Library of Congress or elsewhere in the country. The ATLA Professional Development Committee supports these projects by subsidizing the costs of training.

Submitted by

Judy Knop

ATLA NACO and CONSER Funnels Coordinator 